\title{
The inhibitory effects of berry-derived flavonoids against neurodegenerative processes
}

\author{
David Vauzour, Katerina Vafeiadou, Catarina Rendeiro, Giulia Corona and Jeremy P.E. Spencer* \\ Molecular Nutrition Group, Department of Food and Nutritional Sciences, School of Chemistry, \\ Food and Pharmacy, University of Reading, Reading, UK
}

\begin{abstract}
Evidence suggests that a combination of oxidative stress, neuroinflammation and the formation of endogenous neurotoxins contribute to the underlying neuronal death associated with neurodegenerative diseases. In this study we have investigated the ability of the berry-derived flavonoids to protect against neuronal damage induced by neuroinflammation and the neurotoxin 5-S-cysteinyl-dopamine. The flavanols (+)-catechin and (-)-epicatechin, but not the anthocyanidin pelargonidin, were observed to attenuate LPS/IFN- $\gamma$-induced TNF- $\alpha$ production in glial cells and associated neuronal injury. In contrast, pre-treatment of primary cortical neurons with pelargonidin, (+)-catechin and (-)-epicatechin $(0.1$ and $0.3 \mu \mathrm{M})$ resulted in concentration-dependant protection against 5-S-cysteinyl-dopamine-induced neurotoxicity. Together these data suggest that berry-derived flavonoids may offer some protection against the neuronal injury relevant to the aetiology of the Parkinson's and Alzheimer's diseases.
\end{abstract}

Keywords: Brain, neuroinflammation, flavonoids, Parkinson disease, neurotoxins

\section{Introduction}

Abundant evidence exists to suggest that increased oxidative stress may contribute to the neuropathology of agerelated brain disorders such as Alzheimer's and Parkinson's disease [11,21]. Although the precise mechanisms of neuronal death in these disorders remains uncertain, it is likely that a combination of elevated oxidative stress, the formation endogenous neurotoxic cysteinyl-catecholamine conjugates [26] and neuroinflammation [9] are believed to play a role in the underlying pathogenesis. For example, 5-S-cysteinyl-dopamine (CysDA) has been shown to possess strong neurotoxicity and may initiate a sustained increase in intracellular reactive oxygen species (ROS) in neurons leading to DNA oxidation, caspase-3 activation and delayed neuronal death [28]. Furthermore, glial cells may become activated by various inflammatory stimuli to produce cytokines such as TNF- $\alpha$ which contribute to neuronal injury [7]. Deleterious effects of TNF- $\alpha$ have been reported [19], and appear to be mediated by its binding to neuronal tumour necrosis factor receptor- 1 (TNFR1) and the subsequent activation of downstream caspase- 8 and caspase-3-mediated apoptotic pathways [29].

Recent studies have focused on the ability of dietary-derived phenolic compounds to protect against neuronal damage resulting from aging and other neurodegenerative processes [18, 32, 38]. Much attention has centred on the potential neuroprotective effects of flavonoids, which have been shown to protect against age-related cognitive decline [12,39], against 6-hydroxydopamine neurotoxicity [8] and against 1-methyl-4-phenyl-1,2,3,6-tetrahydropyridine

*Corresponding author: J.P.E. Spencer, School of Chemistry, Food and Pharmacy, The University of Reading, PO Box 226, Whiteknights, Reading, RG2 6AP, UK. Tel.: +44 118378 8724; Fax: +44 118931 0080; E-mail: j.p.e.spencer@ reading.ac.uk. 
(MPTP) lesioning of the nigrostriatal tract [16]. For example, the consumption of flavonoid-rich blueberries and strawberries has been shown to reverse age-related cognitive and motor behavioural deficits [12, 27, 35, 39], whilst green tea and isolated EGCG protect against MPTP induced striatal dopamine depletion and neuronal loss [16] in animal models. Furthermore, flavonoids have also been shown to inhibit inflammatory processes mediated by glial cells [32], with the flavones wogonin and baicalein [5, 14], the flavonol quercetin [6], the isoflavone genistein [37] and the flavanols catechin and epigallocatechin gallate [10, 17] all expressing anti-inflammatory activity.

In the present study, we provide evidence that both 5-S-cysteinyl-dopamine and LPS/IFN- $\gamma$-induced TNF- $\alpha$ release resulted in concentration-dependent neurotoxicity. However, pre-treating the neuronal cells with the berry-derived flavonoids pelargonidin, (+)-catechin and (-)-epicatechin significantly decreased the injury elicited by these endogenous neurotoxins at low micromolar concentrations. The same results were observed for LPS/IFN- $\gamma$-induced TNF- $\alpha$ release treated glial cells for the flavanols (+)-catechin and (-)-epicatechin, but not the anthocyanidin pelargonidin.

\section{Materials and methods}

\subsection{Materials}

The following chemicals were obtained from Sigma Chemical Company (Poole, UK): (+)-catechin, (-)-epicatechin, bacterial endotoxin LPS (Escherichia Coli, serotype 0127:B8) and mouse interferon- $\gamma($ IFN- $\gamma$ )). Pelargonidin was purchased from Extrasynthese (Genay, France). The 5-S-CysDA was prepared as previously described [36]. All tissue culture reagents were purchased from Invitrogen (Paisley, UK). Ultrapure water (18.2 M $\Omega . \mathrm{cm}$ ) passed through a purification system (Purite Ltd, Oxon, UK) was used for all purposes.

\subsection{Cell culture}

Neuronal cells: Primary culture of neuronal cells were prepared as described previously [34]. Cells (106/ml) were plated in a serum-free medium composed of a mixture of DMEM and F-12 nutrient (1:1 v/v) supplemented with glucose $(33 \mathrm{mM})$, glutamine $(2 \mathrm{mM})$, sodium bicarbonate $(6.5 \mathrm{mM})$, HEPES $(\mathrm{pH} 7.4,5 \mathrm{mM})$, streptomycin $(100 \mu \mathrm{g} / \mathrm{ml})$ and penicillin (100 UI/ml) (all Invitrogen, Paisley, UK). A mixture of hormones and salts composed of insulin $(25 \mu \mathrm{g} / \mathrm{ml})$, transferrin $(100 \mu \mathrm{g} / \mathrm{ml})$, putrescine $(60 \mu \mathrm{g} / \mathrm{ml})$, progesterone $(20 \mathrm{nM})$ and sodium selenate $(30 \mathrm{nM})$ (all from Sigma, Poole, Dorset, UK) was also added to the culture medium. Cells were cultured at $37^{\circ} \mathrm{C}$ in a humidified atmosphere of $95 \%$ air and $5 \% \mathrm{CO}_{2}$ and after 5-6 days the vast majority of cells were neuronal ( $>98 \%$ ) with $<2 \%$ astrocytes as determined by $\beta$-tubulin and GFAP immunocytochemistry respectively as reported previously [4].

Glial cells: Primary culture of glial cells was conducted as described previously [30]. Cells $\left(5 \times 10^{5} / \mathrm{mL}\right) \mathrm{were}$ cultured in a medium composed of Dulbecco's Modified Eagle Medium and F-12 nutrient (1:1 v/v) supplemented with glucose $(33 \mathrm{mmol} / \mathrm{L})$, glutamine $(2 \mathrm{mmol} / \mathrm{L})$, sodium bicarbonate $(13 \mathrm{mmol} / \mathrm{L})$, HEPES buffer $(\mathrm{pH} 7.4,5 \mathrm{mmol} / \mathrm{L})$, streptomycin $(100 \mu \mathrm{g} / \mathrm{mL})$, penicillin $(100 \mathrm{IU} / \mathrm{mL})$, and $10 \%$ heat inactivated $\mathrm{FBS}\left(37^{\circ} \mathrm{C} ; 5 \% \mathrm{CO}_{2}\right)$. The culture medium was replaced once per week and glial cells were used following 14-16 days in vitro, at which time they consisted of astrocytes $(\sim 90 \%)$ and microglia $(\sim 10 \%)$. Cell morphology was determined by immunocytochemistry with antibodies against GFAP (astrocytes) and $\beta$-tubulin (neurons) as reported previously [4].

\subsection{Cell treatments}

Medium levels of TNF- $\alpha$ were determined using a mouse enzyme-linked immunosorbent assay (R\&D Systems, Abingdon, UK) following the manufacturer instructions. To investigate the ability of flavonoids to inhibit TNF- $\alpha$ release, glial cells were pre-treated with different concentrations of flavonoid $(0.1$ and $0.3 \mu \mathrm{mol} / \mathrm{L})$ or vehicle (methanol) for $24 \mathrm{~h}$ prior to the addition of LPS $(1 \mu \mathrm{g} / \mathrm{mL})$ and IFN- $\gamma(10 \mathrm{ng} / \mathrm{mL})$ for $24 \mathrm{~h}$. To avoid chemical interaction between the flavanones and LPS or IFN- $\gamma$ cells were washed thoroughly with phosphate buffer saline (PBS) supplemented with glucose $(33 \mathrm{mmol} / \mathrm{L})$ prior to their addition. Following exposure to LPS and IFN- $\gamma$, the medium was retained for $\mathrm{TNF}-\alpha$ analysis. 
To investigate the protective effects of flavonoids, neurons were pre-treated with (+)-catechin, (-)-epicatechin and pelargonidin $(0.1$ and $0.3 \mu \mathrm{M})$ for $18 \mathrm{~h}$ prior the addition of CysDA $(100 \mu \mathrm{M})$ for a further $24 \mathrm{~h}$. Following exposure, cultures were washed twice with sterile PBS before the addition of Alamar Blue solution (10\% v/v) in DMEM:F12. Plates were then returned to the incubator for 2, 3 hours, before fluorescence was measured (Ex: $540 \mathrm{~nm} ; \mathrm{Em}: 612 \mathrm{~nm}$ ) on a Tecan GENios multiplate reader (Tecan GENios, Theale, UK). Results were expressed as percentage of neuronal injury relative to vehicle treated cells.

\subsection{Statistical analysis}

All results are expressed as means \pm SD of three separate experiments unless otherwise stated. The statistical evaluation of the results was performed by one-way analysis of variance (ANOVA) followed by a post-hoc $t$-test using GraphPad InStat version 3.05 (GraphPad Software, San Diego, CA, USA). Significance was defined as $p<0.05$. Significant changes are indicated as follows: $* * * p<0.001 ; * * p<0.01 ; * p<0.05$ and $\mathrm{a}=p<0.001 ; \mathrm{b}=p<0.01$; $\mathrm{c}=p<0.05$.

\section{Results}

\subsection{Flavonoids protect neurons challenged with 5-S-cysteinyl-dopamine}

Pelargonidin and the flavanols (+)-catechin and (-)-epicatechin $(0.1-3.0 \mu \mathrm{M})$ did not induce neuronal injury as assessed by the Alamar blue assay $24 \mathrm{~h}$ post exposure ( $>98 \%$ compared to vehicle, 100). Exposure of primary cortical neurons to $5-S$-cysteinyl-dopamine $(10-500 \mu \mathrm{M})$ led to concentration-dependent increases in neuronal injury $\left(\mathrm{IC}_{50}=100.2 \pm 2.1 \mu \mathrm{M}\right)$ when assessed $24 \mathrm{~h}$ after exposure (Fig. 1). The strongest neuroprotective effect was observed when neurons were pre-treated with pelargonidin $(0.1-3 \mu \mathrm{M})$. Indeed, concentrations ranging from 0.1 to $1 \mu \mathrm{M}$ significantly protected neurons from injury induced by $5-S$-CysDA (Fig. $2 \mathrm{~A}$ ), with $1 \mu \mathrm{M}$ being the most potent $(90.1 \pm 4.2 \%, p<0.001)$. Pelargonidin $(3 \mu \mathrm{M})$ was also observed to be significantly protective, although to a lesser degree $(34.2 \pm 2.5 \%, p<0.001)$. Significant protection against 5 -S-CysDA-induced neuronal damage was also observed for (-)-epicatechin $(0.1$ to $3 \mu \mathrm{M})$, the greatest degree of protection apparent at the $1 \mu \mathrm{M}$ concentration $(46.7 \pm 4.0 \% ; p<0.001)$ (Fig 2B). Finally, a small but significant protection was also afforded by (+)-catechin, with the $300 \mathrm{nM}$ concentration being the most protective $(19.0 \pm 5.0 \% ; p<0.05)$ (Fig 2C).

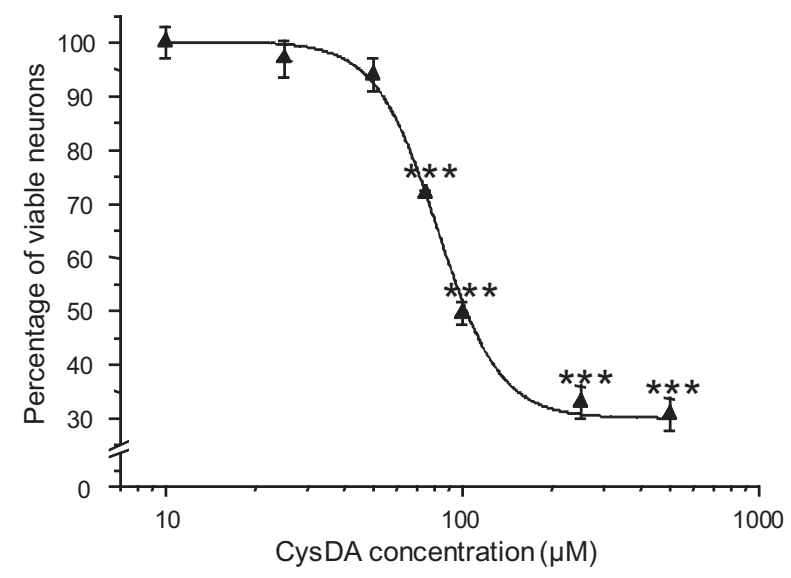

Fig. 1. 5-S-cysteinyl-dopamine induces toxicity on primary cortical neurons. 5, 6 days in vitro primary neurons were exposed to 5-S-cysteinyldopamine $(10-500 \mu \mathrm{M})$ or vehicle for $24 \mathrm{~h}$. After $24 \mathrm{~h}$, cell viability was determined by Alamar blue reduction. Results are expressed as mean \pm SD of quadruplicate wells from single experiments repeated three times with similar results (***p $<0.001$; compared with control, as analysed by one way ANOVA followed by post-hoc $t$-test). 
A

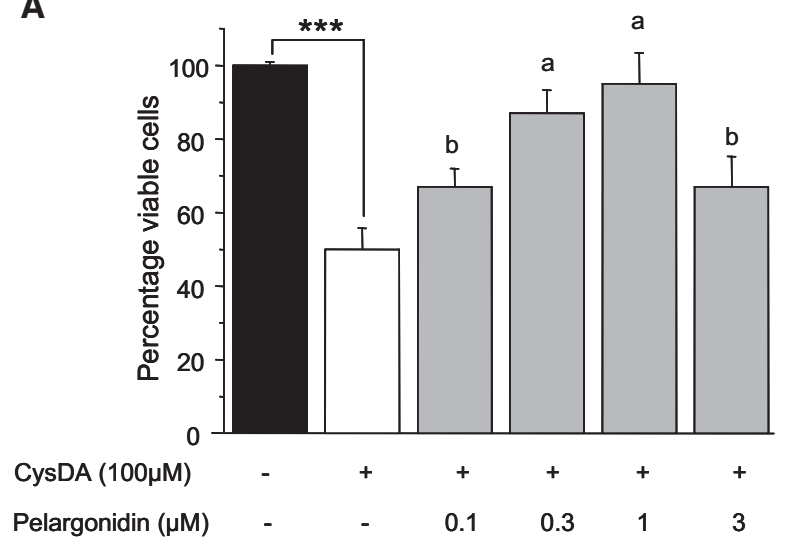

B

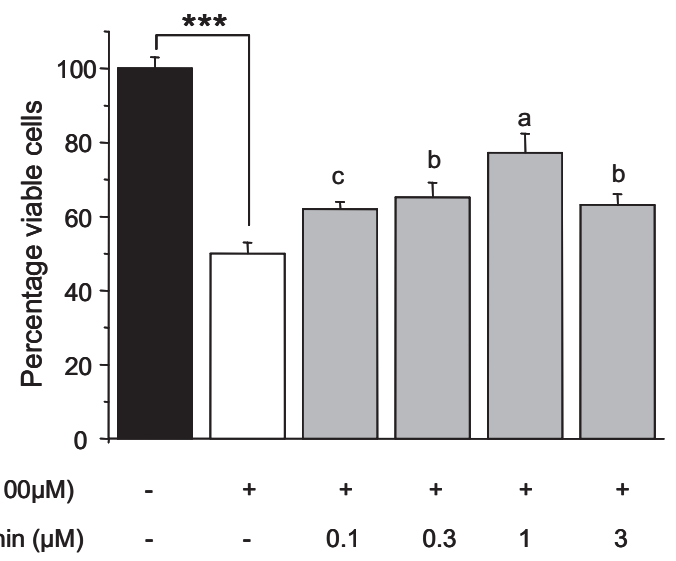

C

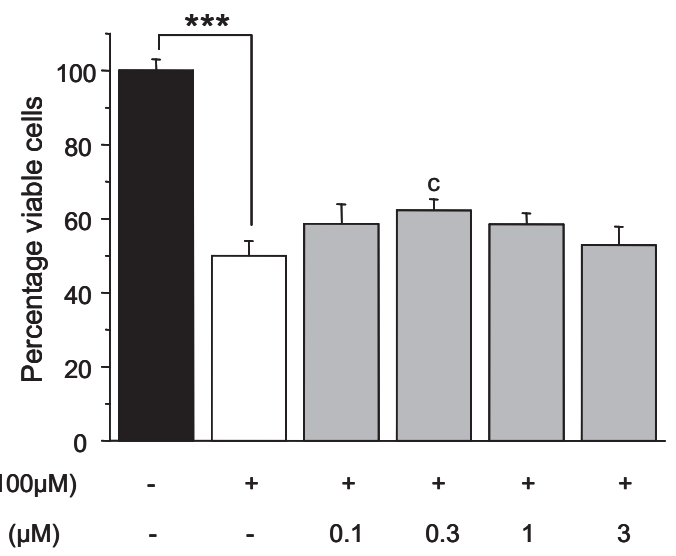

Fig. 2. Protective effects of flavonoids against 5-S-cysteinyl-dopamine-induced neuronal injury. Following pre-treatment with (A) pelargonidin, (B) (-)-epicatechin or (C) (+)-catechin $(0.1-3 \mu \mathrm{M})$ for $18 \mathrm{~h}, 5-6$ DIV primary neurons were exposed to 5-S-cysteinyl-dopamine (100 $\mu \mathrm{M})$ for $24 \mathrm{~h}$. Alamar Blue solution (10\% v/v) was added to plates and they were returned to the incubator for $2-3 \mathrm{~h}$, before fluorescence was measured (Ex: $540 \mathrm{~nm}$; Em: $612 \mathrm{~nm}$ ). Results are expressed as mean \pm SD of quadruplicate wells from single experiments repeated three times with similar results. Data were analysed by one way ANOVA followed by post-hoc $t$-test. $*^{* *} p<0.001$ respresent a significant decrease of neuronal viability relative to control; $\mathrm{a}=p<0.001, \mathrm{~b}=p<0.01, \mathrm{c}=p<0.05$ represent a significant increase in neuronal viability relative CysDA treated cells. 


\subsection{Inhibitory effect of flavonoids on LPS/IFN- $\gamma$-induced TNF-a release}

Pelargonidin and the flavanols (+)-catechin and (-)-epicatechin $(0.1-3.0 \mu \mathrm{M})$ did not induce glial cell injury as assessed by the Alamar blue assay $24 \mathrm{~h}$ post exposure. Treatment of glial cells with LPS $(1 \mu \mathrm{g} / \mathrm{mL})$ and IFN- $\gamma$ $(10 \mathrm{ng} / \mathrm{mL})$ for $24 \mathrm{~h}$ resulted in a significant increase in TNF- $\alpha$ production $(p<0.001, n=6)$ (Fig. 3). However, preincubation of glial cells with either (+)-catechin or (-)-epicatechin $(0.1-3 \mu \mathrm{M} ; 24 \mathrm{~h})$, prior to LPS/IFN- $\gamma$ exposure, resulted in a significant decrease in medium TNF- $\alpha$ levels (Fig. 3A and B). In contrast, pre-treatment with pelargonidin (0.1-3 $\mu \mathrm{M} ; 24 \mathrm{~h}$ ) had no significant effect on LPS/IFN- $\gamma$-induced TNF- $\alpha$ release (Fig. 3C).

\section{Discussion}

Abundant evidence exists to suggest that increased oxidative stress may contribute to the neuropathology of age-related brain disorders such as Alzheimer's and Parkinson's diseases [11, 21]. In this study, we show that 5-cysteinyl conjugates of dopamine possess a strong cytotoxicity towards primary cortical neurons. 5-S-CysDA, have been reported previously to be neurotoxic by inducing both oxidative DNA base modification and the activation of caspase-3 activity in neurons [20,26]. Once formed, 5-S-CysDA may be further oxidised, yielding more complex conjugated species, such as DHBT-1 [24], an event which may be accelerated in the presence of peroxynitrite [33], a powerful oxidant and cytotoxic molecule formed from the reaction of nitric oxide $(\mathrm{NO})^{\bullet}$ with superoxide $\left(\mathrm{O}_{2}-\right)$ [13]. Presence of such oxidant molecules may be the results of activation of the iNOS enzyme, an event triggered under neuro-inflammatory processes. Indeed, under inflammatory conditions, excess release of cytokines, such as TNF- $\alpha$, is a central event in glial-induced neurotoxicity. Such detrimental actions of TNF- $\alpha$ induced neurotoxicity have had been reported in neuronal models [19], and are thought to be the result of the activation iNOS expression and the subsequent $\mathrm{NO}^{\bullet}$ release, thus enhancing its neurotoxic potential [15]. As a consequence, there has been much interest in the development of novel therapeutic agents that can selectively attenuate neurotoxins-induced toxicity.

Recent evidence from human, animal and cell studies suggest that flavonoids may exert neuroprotective effects $[3,8$, 25]. In the brain, the potential actions of flavonoids on neurons will be influenced by interactions with both astrocytes and microglia, which occupy the majority of the brain volume and play a key role in the maintenance of neuronal integrity. In this study, we show that specific berry-derived flavonoids are capable of inhibiting glial activation and of reducing cysteinyl-dopamine neurotoxicity at physiologically achievable plasma concentrations (nanomolar). Whilst the three flavonoids tested (pelargonidin, (+)-catechin and (-)-epicatechin) were able to decrease the neuronal cell death in primary neurons challenged with CysDA, only the flavanols (+)-catechin and (-)-epicatechin were able to inhibit TNF- $\alpha$, production in LPS/IFN- $\gamma$-activated glial cells. Such protective effects may be the results of an inhibition of the inducible nitric oxide synthase (iNOS) in glial cells as reported previously for the flavanone naringenin [30], or an activation of the detoxification enzymes such as the glutathione- $S$-transferase as observed previously in primary neurons in presence of (-)-epicatechin [4]. Action of such enzymes may decrease the neurotoxic potential of some molecules, as observed for quercetin where its neurotoxicity was significantly reduced by glial cell metabolism, notably by its conversion to $2^{\prime}$-glutathionyl quercetin [31].

Although flavonoids have been reported to exert strong antioxidant effects in vitro, accumulating evidence suggests that dietary polyphenols may cross the blood brain barrier [2,40], accumulate in the brain at nanomolar concentrations $[1,2]$ and exert neuromodulatory effects through selective actions on different components of a number of protein kinase and lipid kinase signalling cascades, such as PI 3-kinase, Akt/PKB, tyrosine kinase, PKC and members of the MAP kinase family [23]. Modulation of these pathways may underlie the ability of berry-derived flavonoids to exert their protective effects, as previously reported for the flavan-3-ol, (-)-epicatechin, which has been observed to stimulate the phosphorylation of the transcription factor cAMP-response element binding protein (CREB), a regulator of neuronal viability and synaptic plasticity [22]. Moreover, both hesperetin and 5-nitro-hesperetin were also effective at preventing neuronal apoptosis via a mechanism involving the activation of both Akt/PKB and ERK1/2 [34]. Further research is required in order to establish the underlying mechanisms involving the neuroprotective effects of the berry-derived flavonoids. 

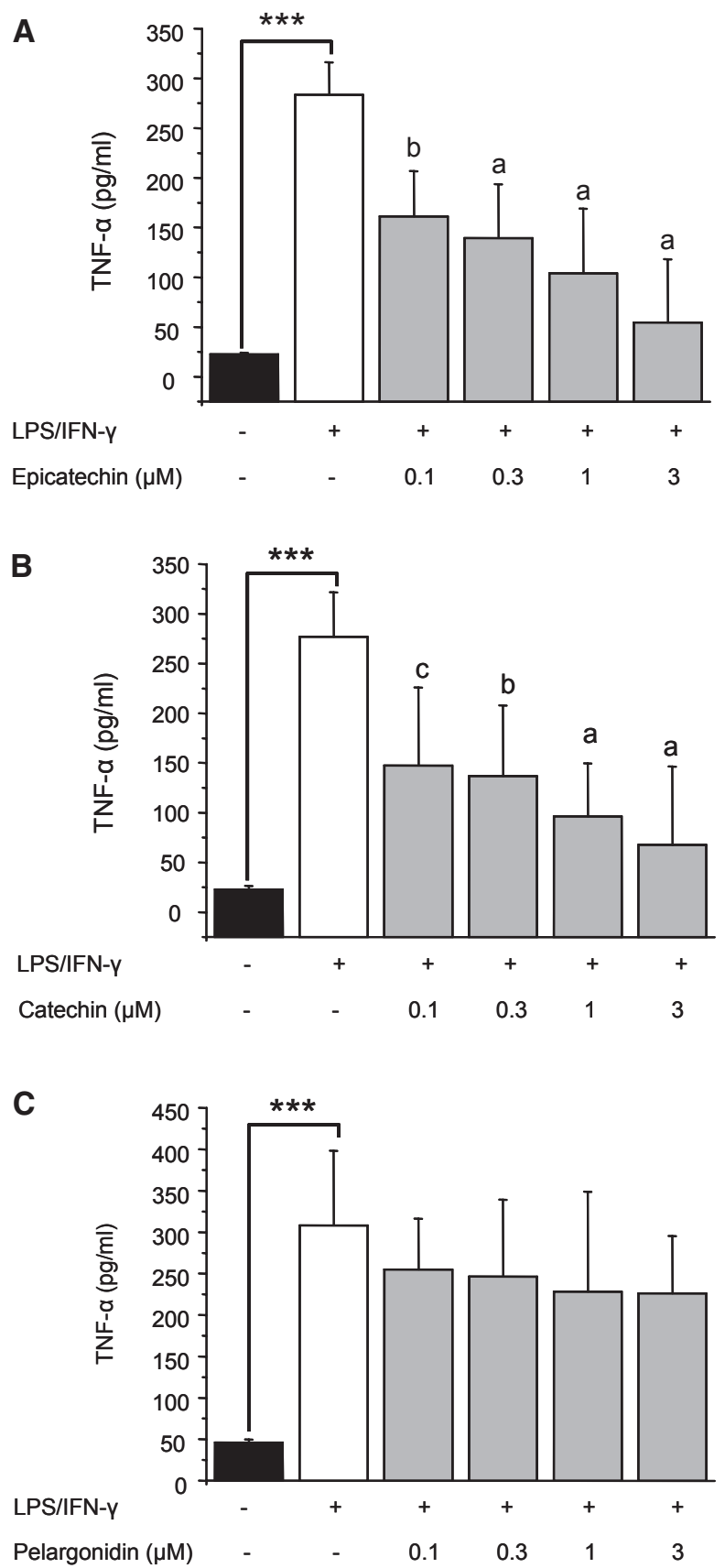

Fig. 3. Flavonoids inhibit TNF- $\alpha$ production in LPS/IFN- $\gamma$ activated primary glial cells. Cells were treated with LPS $(1 \mu \mathrm{g} / \mathrm{mL})$ and IFN- $\gamma$ $(10 \mathrm{ng} / \mathrm{mL})$ for $24 \mathrm{~h}$ alone (LPS/IFN- $\gamma$ group) or pre-treated with naringenin (A), (-)-epicatechin (B), (+)-catechin or (C), pelargonidin $(0.1-3 \mu \mathrm{mol} / \mathrm{L})$ for $24 \mathrm{~h}$ before LPS/IFN- $\gamma$ activation for another $24 \mathrm{~h}$. After incubation TNF- $\alpha$ concentrations were measured in the cell culture medium by enzyme-linked immunosorbent assay. Results are presented as means \pm SD of three independent experiments. *** $p<0.001$, indicates significant increase in TNF- $\alpha$ production relative to control; $\mathrm{a}=p<0.001 ; \mathrm{b}=p<0.01 ; \mathrm{c}=p<0.05$ indicates significant decrease in TNF- $\alpha$ production relative to LPS/IFN- $\gamma$ group. 


\section{References}

[1] M. Abd El-Mohsen, H. Bayele, G. Kuhnle, G. Gibson, E. Debnam, S. Kaila Srai, C. Rice-Evans and J.P. Spencer, Distribution of [3H]transresveratrol in rat tissues following oral administration, British Journal ofNutrition 96 (2006), 62-70.

[2] M.M. Abd El Mohsen, G. Kuhnle, A.R. Rechner, H. Schroeter, S. Rose, P. Jenner and C.A. Rice-Evans, Uptake and metabolism of epicatechin and its access to the brain after oral ingestion, Free Radical Biology and Medicine 33 (2002), 1693-1702.

[3] C. Andres-Lacueva, B. Shukitt-Hale, R.L. Galli, O. Jauregui, R.M. Lamuela-Raventos and J.A. Joseph, Anthocyanins in aged blueberry-fed rats are found centrally and may enhance memory, Nutrition Neuroscience 8 (2005), 111-120.

[4] P.K. Bahia, M. Rattray and R.J. Williams, Dietary flavonoid (-)epicatechin stimulates phosphatidylinositol 3-kinase-dependent anti-oxidant response element activity and up-regulates glutathione in cortical astrocytes, Journal of Neurochemistry 106 (2008), $2194-2204$.

[5] C.J. Chen, S.L. Raung, S.L. Liao and S.Y. Chen, Inhibition of inducible nitric oxide synthase expression by baicalein in endotoxin/cytokinestimulated microglia, Biochemical Pharmacology 67 (2004), 957-965.

[6] J.C. Chen, F.M. Ho, C. Pei-Dawn Lee, C.P. Chen, K.C. Jeng, H.B. Hsu, S.T. Lee, W. Wen Tung and W.W. Lin, Inhibition of iNOS gene expression by quercetin is mediated by the inhibition of IkappaB kinase, nuclear factor-kappa B and STAT1, and depends on heme oxygenase-1 induction in mouse BV-2 microglia, European Journal of Pharmacology 521 (2005), 9-20.

[7] J.M. Craft, D.M. Watterson and L.J. Van Eldik, Neuroinflammation: A potential therapeutic target, Expert Opinion on Therapeutic Targets 9 (2005), 887-900.

[8] R.L. Galli, B. Shukitt-Hale, K.A. Youdim and J.A. Joseph, Fruit polyphenolics and brain aging: Nutritional interventions targeting age-related neuronal and behavioral deficits, Annals of the New York Academy of Science 959 (2002), 128-132.

[9] E.C. Hirsch, S. Hunot and A. Hartmann, Neuroinflammatory processes in Parkinson's disease, Parkinsonism and Related Disorders 11(Suppl. 1) (2005), S9-S15.

[10] Q. Huang, L.J. Wu, S. Tashiro, H.Y. Gao, S. Onodera and T. Ikejima, (+)-Catechin, an ingredient of green tea, protects murine microglia from oxidative stress-induced DNA damage and cell cycle arrest, Journal of Pharmacological Sciences 98 (2005), 16-24.

[11] P. Jenner, Oxidative stress and Parkinson's disease, Handbook of Clinical Neurology 83 (2007), 507-520.

[12] J.A. Joseph, B. Shukitt-Hale, N.A. Denisova, D. Bielinski, A. Martin, J.J. McEwen and P.C. Bickford, Reversals of age-related declines in neuronal signal transduction, cognitive, and motor behavioral deficits with blueberry, spinach, or strawberry dietary supplementation, Journal of Neuroscience 19 (1999), 8114-8121.

[13] W.H. Koppenol, J.J. Moreno, W.A. Pryor, H. Ischiropoulos and J.S. Beckman, Peroxynitrite, a cloaked oxidant formed by nitric oxide and superoxide, Chemical Research in Toxicology 5 (1992), 834-842.

[14] H. Lee, Y.O. Kim, H. Kim, S.Y. Kim, H.S. Noh, S.S. Kang, G.J. Cho, W.S. Choi and K. Suk, Flavonoid wogonin from medicinal herb is neuroprotective by inhibiting inflammatory activation of microglia, FASEB Journal 17 (2003), 1943-1944.

[15] S.M. Lee, T.Y. Yune, S.J. Kim, Y.C. Kim, Y.J. Oh, G.J. Markelonis and T.H. Oh, Minocycline inhibits apoptotic cell death via attenuation of TNF-alpha expression following iNOS/NO induction by lipopolysaccharide in neuron/glia co-cultures, Journal of Neurochemistry 91 (2004), 568-578.

[16] Y. Levites, O. Weinreb, G. Maor, M.B. Youdim and S. Mandel, Green tea polyphenol (-)-epigallocatechin-3-gallate prevents N-methyl-4phenyl-1,2,3,6-tetrahydropyridine-induced dopaminergic neurodegeneration, Journal of Neurochemistry 78 (2001), 1073-1082.

[17] R. Li, Y.G. Huang, D. Fang and W.D. Le, (-)-Epigallocatechin gallate inhibits lipopolysaccharide-induced microglial activation and protects against inflammation-mediated dopaminergic neuronal injury, Journal of Neuroscience Research 78 (2004), 723-731.

[18] P. Maher, A comparison of the neurotrophic activities of the flavonoid fisetin and some of its derivatives, Free Radical Research 40 (2006), 1105-1111.

[19] M.K. McCoy, T.N. Martinez, K.A. Ruhn, D.E. Szymkowski, C.G. Smith, B.R. Botterman, K.E. Tansey and M.G. Tansey, Blocking soluble tumor necrosis factor signaling with dominant-negative tumor necrosis factor inhibitor attenuates loss of dopaminergic neurons in models of Parkinson's disease, Journal of Neuroscience 26 (2006), 9365-9375.

[20] L. Mosca, E. Lendaro, M. d'Erme, S. Marcellini, S. Moretti and M.A. Rosei, 5-S-Cysteinyl-dopamine effect on the human dopaminergic neuroblastoma cell line SH-SY5Y, Neurochemistry International 49 (2006), 262-269.

[21] L.M. Sayre, G. Perry and M.A. Smith, Oxidative stress and neurotoxicity, Chemical Research in Toxicology 21 (2008), $172-188$.

[22] H. Schroeter, P. Bahia, J.P. Spencer, O. Sheppard, M. Rattray, E. Cadenas, C. Rice-Evans and R.J. Williams, (-)Epicatechin stimulates ERK-dependent cyclic AMP response element activity and up-regulates GluR2 in cortical neurons, Journal of Neurochemistry 101 (2007), 1596-1606.

[23] H. Schroeter, C. Boyd, J.P. Spencer, R.J. Williams, E. Cadenas and C. Rice-Evans, MAPK signaling in neurodegeneration: Influences of flavonoids and of nitric oxide, Neurobioly of Aging 23 (2002), 861-880.

[24] X.M. Shen, F. Zhang and G. Dryhurst, Oxidation of dopamine in the presence of cysteine: Characterization of new toxic products, Chemical Research in Toxicology 10 (1997), 147-155.

[25] J.P. Spencer, Food for thought: The role of dietary flavonoids in enhancing human memory, learning and neuro-cognitive performance, Proceedings of the Nutrition Society 67 (2008), 238-252. 
[26] J.P. Spencer, P. Jenner, S.E. Daniel, A.J. Lees, D.C. Marsden and B. Halliwell, Conjugates of catecholamines with cysteine and GSH in Parkinson's disease: Possible mechanisms of formation involving reactive oxygen species, Journal of Neurochemistry 71 (1998), $2112-2122$.

[27] J.P. Spencer, D. Vauzour and C. Rendeiro, Flavonoids and cognition: The molecular mechanisms underlying their behavioural effects, Archives of Biochemistry and Biophysics 492 (2009), 1-9.

[28] J.P. Spencer, M. Whiteman, P. Jenner and B. Halliwell, 5-s-Cysteinyl-conjugates of catecholamines induce cell damage, extensive DNA base modification and increases in caspase-3 activity in neurons, Journal of Neurochemistry 81 (2002), 122-129.

[29] D.L. Taylor, F. Jones, E.S. Kubota and J.M. Pocock, Stimulation of microglial metabotropic glutamate receptor mGlu2 triggers tumor necrosis factor alpha-induced neurotoxicity in concert with microglial-derived Fas ligand, Journal of Neuroscience 25 (2005), $2952-2964$.

[30] K. Vafeiadou, D. Vauzour, H.Y. Lee, A. Rodriguez-Mateos, R.J. Williams and J.P. Spencer, The citrus flavanone naringenin inhibits inflammatory signalling in glial cells and protects against neuroinflammatory injury, Archives of Biochemistry and Biophysics 484 (2009), 100-109.

[31] K. Vafeiadou, D. Vauzour, A. Rodriguez-Mateos, M. Whiteman, R.J. Williams and J.P. Spencer, Glial metabolism of quercetin reduces its neurotoxic potential, Archives of Biochemistry and Biophysics 478 (2008), 195-200.

[32] K. Vafeiadou, D. Vauzour and J.P. Spencer, Neuroinflammation and its modulation by flavonoids, Endocrine, Metabolic \& Immune Disorders - Drug Targets 7 (2007), 211-224.

[33] D. Vauzour, G. Ravaioli, K. Vafeiadou, A. Rodriguez-Mateos, C. Angeloni and J.P. Spencer, Peroxynitrite induced formation of the neurotoxins 5-S-cysteinyl-dopamine and DHBT-1: Implications for Parkinson's disease and protection by polyphenols, Archives of Biochemistry and Biophysics 476 (2008), 145-151.

[34] D. Vauzour, K. Vafeiadou, C. Rice-Evans, R.J. Williams and J.P. Spencer, Activation of pro-survival Akt and ERK1/2 signalling pathways underlie the anti-apoptotic effects of flavanones in cortical neurons, Journal of Neurochemistry 103 (2007), 1355-1367.

[35] D. Vauzour, K. Vafeiadou, A. Rodriguez-Mateos, C. Rendeiro and J.P. Spencer, The neuroprotective potential of flavonoids: A multiplicity of effects, Genes and Nutrition 3 (2008), 115-126.

[36] D. Vauzour, K. Vafeiadou and J.P. Spencer, Inhibition of the formation of the neurotoxin 5-S-cysteinyl-dopamine by polyphenols, Biochemical and Biophysical Research Communications 362 (2007), 340-346.

[37] X. Wang, S. Chen, G. Ma, M. Ye and G. Lu, Genistein protects dopaminergic neurons by inhibiting microglial activation, Neuroreport 16 (2005), 267-270.

[38] O. Weinreb, S. Mandel, T. Amit and M.B. Youdim, Neurological mechanisms of green tea polyphenols in Alzheimer's and Parkinson's diseases, Journal of Nutritional Biochemistry 15 (2004), 506-516.

[39] C.M. Williams, M.A. El Mohsen, D. Vauzour, C. Rendeiro, L.T. Butler, J.A. Ellis, M. Whiteman and J.P. Spencer, Blueberry-induced changes in spatial working memory correlate with changes in hippocampal CREB phosphorylation and brain-derived neurotrophic factor (BDNF) levels, Free Radicals in Biology and Medicine 45 (2008), 295-305.

[40] K.A. Youdim, M.Z. Qaiser, D.J. Begley, C.A. Rice-Evans and N.J. Abbott, Flavonoid permeability across an in situ model of the blood-brain barrier, Free Radical Biology and Medicine 36 (2004), 592-604. 